\title{
El comportamiento sintáctico de los predicados existenciales en catalán*
}

\author{
Gemma RigaU
}

UNIVERSIDAD AUTÓNOMA DE BARCELONA

El objetivo de mi exposición es llamar la atención sobre algunos aspectos de sintaxis dialectal del catalán poco estudiados. Sabido es que en los trabajos de dialectología románica la variación fonética, la morfológica y la léxica constituyen el centro de interés de los estudiosos. Se ha comentado a menudo la poca atención de la dialectología a la sintaxis. No obstante, ello no significa que la variación sintáctica no exista o que en los estudios de dialectología catalana no se haga referencia a ella. Hay que reconocer que en las descripciones dialectales encontramos observaciones sintácticas, pero a menudo demasiado ligadas a la morfología. Ciertamente, carecemos de estudios monográficos sobre las propiedades sintácticas de los dialectos del catalán.

Mi intención aquí es describir el comportamiento de los predicados existenciales o locativos en los principales dialectos del catalán. Los datos que presentaré pertenecen básicamente a seis dialectos catalanes: catalán central, catalán noroccidental, valenciano, baleárico, alguerés y rosellonés ${ }^{1}$.

1. La mayoría de dialectos catalanes poseen dos verbos existenciales, también llamados verbos locativos o de presentación: ser (o ésser) y haver que aparece junto al pronombre átono locativo hi. Ser corresponde aproxima-

* Este trabajo forma parte de un estudio subvencionado por la DGICYT, Ministerio de Educación y Ciencia (PB 89-0324).

${ }^{1}$ El alguerés se habla en L'Alguer, en la costa noroeste de la isla de Cerdeña, desde el siglo XIV. Este habla catalana ha recibido mucha influencia del sardo y más recientemente del italiano. Actualmente cuenta con unos 5.000 hablantes.

El catalán hablado en el Rosellón, el Vallespir, el Conflent y el Capcir —en el sureste de Franciase conoce con el nombre de rosellonés. 
damente al existencial estar del español y del gallego. El predicativo haver-hi necesariamente aparece con el pronombre clítico $h i$ incorporado al verbo $h a$ ver en todos los tiempos verbales, formando un único elemento léxico. Ambos verbos existenciales seleccionan un argumento que recibe el valor semántico o papel temático «locativo» y otro que recibe el valor semántico o papel temático de «tema». Asimismo, en la mayoría de los dialectos catalanes, ambos verbos pueden aparecer con un sintagma nominal (SN) definido, tal como se muestra en los apartados (1) y (2).

(1) a. No hi ha el director. no loc. ha (=hay) el director «No está el director»

b. No hi ha en Pere. no loc. ha (=hay) Pedro «No está Pedro»

(2) a. El director no hi és. el director no loc. es «El director no está»

b. En Pere no hi és.

Pedro no loc. es «Pedro no está»

Las frases de (1) muestran que el verbo catalán haver-hi presenta un comportamiento distinto de sus equivalentes español y gallego. En estas lenguas son imposibles construcciones como las de (3).

(3) a. *No hay el director

b. *Non hai o director. (gallego)

Por otro lado, en catalán son posibles, como en español o en gallego, las construcciones con el verbo haver-hi junto a un SN indefinido o un SN sin determinante. Véase en (4).

(4) a. Hay pocos estudiantes.

b. Hai poucos estudiantes. (gallego)

c. Hi ha pocs estudiants (catalán)

d. Hay estudiantes 


\section{e. Hai estudiantes. (gallego) \\ f. Hi ha estudiants (catalán)}

En el caso del predicado catalán haver-hi el valor semántico o papel temático locativo lo absorbe el pronombre clítico $h i$, incorporado léxicamente al verbo. Por lo tanto, si aparece en la frase un sintagma preposicional (SP) o un sintagma adverbial (SAdv) locativo, éste deberá ocupar una posición periférica, de elemento dislocado. El clítico $h i$, que actuará en tal caso como pronombre reasuntivo, será el responsable de relacionar el SP o SAdv con la frase. Véase en (5)

(5) a. A la reunió, no hi havia el director. en la reunión no loc. había el director «El director no estaba en la reunión»

b. No hi havia el director, a la reunió. no loc. había el director, en la reunión «El director no estaba en la reunión»

c. * No havia el director a la reunió. no había el director en la reunión

d. * A la reunió no havia el director en la reunión no había el director

En el caso del verbo ser el locativo no necesariamente debe estar representado por el clítico $h i$, sino que puede coaparecer con un SP o un SAdv, sea o no clítico, tal como se muestra en (6).

(6) a. El director era a la reunió/allà. «El director estaba en la reunión/allí»

b. El director hi era

El director loc. era «El director estaba (aquí/allí)»

Sin embargo, la diferencia entre los verbos ser y haver-hi no reside sólo en el hecho de que el verbo haver-hi aparezca con el locativo incorporado en forma de pronombre átono o clítico y que, en cambio, esta incorporación no se dé si el verbo es ser. A pesar de lo observado en (1) y (2), que muestran que tanto ser como haver-hi pueden presentarse con un SN definido, la aparición de dichos verbos no es libre. Véanlo en (7), donde se observa que los verbos ser y haver-hi están en distribución complementaria. 
(7) a. Hi ha el director.

loc. ha (=hay) el director

«Está el director»

b. *Hi és el director. versus Hi és, el director.

loc. es el director loc es, el director

c. El director hi és.

el director loc. es

«El director está (aquí/allí)»

d. *El director hi ha. versus EL DIRECTOR hi ha.

el director loc. ha el director loc. ha

A fin de dar cuenta de la distribución complementaria que presentan los verbos de (7), defenderemos que el verbo haver-hi es un verbo transitivo que aparece con un objeto directo o argumento interno de la predicación y que el clítico hi impersonaliza la frase. El verbo ser, en cambio, no se comporta como un verbo transitivo, aunque aparezca con un argumento con el valor semántico de tema. Por otro lado, en las frases con el existencial ser no hay ningún elemento que convierta la frase en impersonal.

Con el verbo ser, el argumento con el valor semántico de tema aparecerá como el sujeto gramatical de la frase, tal como se muestra en (8), donde podemos observar que el locativo puede ser pronominal, como en (8a) o no serlo, como en (8b).

(8) a. El director hi és [=(7c)]

TEMA LOCATIVO

b. El director és allà.

TEMA LOCATIVO

Si el verbo es haver-hi, el argumento con el valor semántico de tema actuará como un argumento interno del predicado, como un objeto directo.

(9) $\mathrm{Hi}$ ha el director $(=(7 \mathrm{a}))$

LOCATIVO TEMA

2. Comentaremos en primer lugar las características de las frases con el verbo haver-hi, para pasar a comentar seguidamente las propiedades de las construcciones con ser. 
Hemos asumido que el pronombre clítico $h i$ aparece léxicamente incorporado al verbo, ya que no existe actualmente en catalán el predicado haver. Este verbo sólo actúa como auxiliar aspectual. Que el clítico hi no es un locativo libre, sino un clítico incorporado, lo prueba el hecho de que no pueda ser sustituido por un SP y un SAdv. ${ }^{2}$ Véase en (10).

(10) a. Hi haurà el director. loc. habrá el director «Estará el director»

b. *Allà haurà el director. allí habrá el director

c. ${ }^{*}$ El director haurà a la universitat. el director habrá en la universidad.

En el pasado haver era un predicativo posesivo como tener. En catalán, como en castellano, todavía son patentes ciertas reminiscencias del antiguo predicado haver, tal como muestran las construcciones arcaizantes de (11).

(11) a. Aquesta noia, no l' hauràs pas. esta chica, no la habrás

b. Això costa d' haver. esto cuesta de haber

c. ¡Bien haya el que me aconsejó tal cosa!

d. Bienaventurados los que han de hambre y sed de justicia.

La comparación de las frases de (12) nos permitirá observar la función del pronombre clítico cuando aparece incorporado al predicado haver-hi.

a. L'ampolla no té tap. «La botella no tiene tapón»

2 El clítico $h i$ también se presenta incorporado a verbos que expresan capacidades perceptivas como veure-hi «ver», sentir-hi «oir», palpar-hi «sentir con el tacto», etc.

Este no es el único clítico que se incorpora a un verbo. Este fenómeno se da también con los clíticos definidos y el clítico partitivo en, como en ballar-la "pasarlo mal», anar-se' $n$ «irse». 
b. L'ampolla no porta tap.

«La botella no lleva tapón»

c. No hi ha tap.

no loc. ha tapón

«No hay tapón»

d. *L'ampolla no hi ha tap.

la botella no hay tapón

En (12a) y (12b) los predicativos tenir «tener» y portar «llevar» asignan papel temático locativo a su argumento externo o sujeto oracional y el papel de tema a su argumento interno ${ }^{3}$. Sin embargo, en (12c) y (12d), el clítico $h i$ bloquea la aparición de un argumento externo locativo. Ello es debido a que el pronombre $h i$ absorbe el papel temático locativo destinado al argumento externo y, en consecuencia, un sintagma nominal como l'ampolla no tiene cabida en (12d). Según el análisis de Torrego (1989), el clítico hi que aparece incorporado a haver actuaria como un sujeto locativo.

Por otro lado, el clítico hi actúa como un impersonalizador, o lo que es lo mismo, bloquea la presencia de un nominativo. En (12c) y (12d), el clítico $h i$ impide la presencia de un elemento que realice la función de sujeto. De ahí que la frase (12c) tenga la apariencia de una impersonal. El clítico hi, cuando aparece incorporado al predicativo haver-hi, actúa como el clítico se arbitrario de las construcciones impersonales de $(13)^{4}$.

(13) a. Mañana se elegirá a los representantes.

b. En esta casa, se come poco.

Aceptemos el supuesto de que en todas las lenguas los sintagmas nominales van marcados con caso. En algunas lenguas, como el latín, dicha marca tenía expresión morfológica, en otras, como en catalán o en español, se trata de una marca abstracta sin realización fonética. En consecuencia, si -como hemos dicho- el pronombre $h i$ en las construcciones con el verbo

${ }^{3}$ Para un estudio de los predicados como portadores de papeles temáticos, véase Gràcia (1989).

${ }^{4}$ Obsérvese que construcciones como las de (i), donde verbo y tema concuerdan en persona y número son agramaticales en todos los dialectos. Las frases con haver-hi no son frases personales.

(i) a. *Hi he jo

loc. he yo

b. *Hi heu vosaltres.

loc. habéis vosotros 
haver-hi actúa como un impersonalizador, ningún elemento en nominativo podrá aparecer en estas frases, ya que sólo las frases personales son frases con un sujeto en nominativo. De este modo, se explica que no sea posible la presencia de un pronombre nominativo en las frases con haver-hi. Así se muestra en (14).
a. *Hi ha ell. loc. ha él
b. *Hi ha jo. loc. ha yo

Asumiremos que el caso que recibe el tema del verbo haver-hi es acusativo, el caso propio de un objeto directo. Ahora bien, en algunos dialectos, el tema del verbo haver-hi puede tener la apariencia de un sujeto, ya que concuerda con el verbo. Así ocurre en el catalán central, aunque no en catalán noroccidental. Véase en (15).

(15) a. Hi han els estudiants. (catalán central)

loc. han los estudiantes

«Están los estudiantes»

b. Hi ha els estudiants. (catalán noroccidental)

loc. ha los estudiantes

«Los estudiantes están (aquí/allí)»

Más adelante defenderemos que el tema de (15a) els estudiants sólo concuerda con el verbo en número, no en persona. En (16) puede comprobarse que el SN els estudiants, a pesar de su apariencia de sujeto en (15a), no puede ser sustituido por un pronombre tónico nominativo en ningún dialecto. Ello prueba que no es nominativo el caso que recibe este SN.

(16) a. *Hi han ells.

loc. han ello

b. *Hi ha ells.

loc. ha ellos

Ahora bien, si asumimos que el tema del predicado haver-hi recibe caso acusativo, nos quedará por explicar por qué no es posible representar el tema con un clítico acusativo. ¿Por qué no existe la construcción (17b) como equivalente a (17a), cuando, en cambio, la combinación «clítico acusativo + locativo» se da en catalán en contextos como los de (18)? 
(17) a. Hi ha el director. $(=(7 \mathrm{a}))$

loc ha el director

«Está el director»

b. *L'hi ha.

el loc. ha

(18) En Pere l'hi ha posat, el llibre, a la lleixa.

Pedro lo+loc. ha puesto, el libro, en el estante

La razón de la agramaticalidad de (17b) reside en el clítico $h i$. En (18), el clítico hi no es impersonalizador, mientras que en (17a) sí lo es. Un clítico impersonalizador $h i$ no puede coaparecer con un clítico acusativo. Véanlo en (19). En las frases (19a) y (19b), que pueden recibir una interpretación impersonal, es evidente que el argumento tema recibe acusativo.

(19) a. (A la portada), no hi posa els noms dels autors. (impersonal)

(en la portada) no loc. pone los nombres de los autores

b. (A l'etiqueta), no hi diu el preu. (impersonal)

(en la etiqueta) no loc. dice/pone el precio

c. No els hi posa. (*interpretación impersonal)

no los loc. pone

d. No l' hi diu. (*interpretación impersonal)

no lo loc. dice

Las frases de (19) nos muestran en primer lugar que los SSNN els noms dels autors y el preu están, sin lugar a dudas, en acusativo. En segundo lugar, nos muestran que el clítico hi puede actuar como sujeto locativo impersonalizador, aunque no esté incorporado al verbo ${ }^{5}$. Pues bien, a pesar de tratarse de acusativos, no es posible pronominalizar los argumentos internos de (19a) y (19b). Lo impide la presencia del clítico hi impersonalizador.

En catalán existe, pues, una restricción «clítico impersonalizador $h i+$ clítico acusativo». ¿Cuál es la razón de esta restricción? Una posible explicación podría basarse en el hecho de que los clíticos referenciales, a diferencia de los nombres, tienen propiedades de persona, además de las propiedades de caso,

5 Véanse otros ejemplos de sujetos locativos en Torrego (1989): Aqui comen turistas: Hi mengen turistes. 
de género y de número. En (19c) y (19d) entrarían en conflicto ambos clíticos. El clítico $h i$ inhibidor de la propiedad de persona, impediría la presencia de otro clítico que precise esta propiedad. En cambio, si en lugar de un objeto clítico aparece un SN como en (19a) y (19b), no habrá incompatibilidad, ya que un SN léxico no poseería la propiedad de persona.

También podría apuntarse una solución a la manera de Bonet (1991) que nos permitiera distinguir diferentes rasgos morfológicos para los dos clíticos $h i$ del catalán, el locativo y el locativo-impersonalizador, y dar cuenta así del hecho de que uno es combinable con clíticos acusativos y el otro no. Sea cual sea la explicación, vemos que el hecho de que no sea pronominalizable el SN argumento interno del verbo haver-hi ejemplificado en (17b), responde a un fenómeno general y que ello no nos ha de impedir analizar este argumento interno como un acusativo.

\section{2. «SER» $(O \ll E S S E R »)$}

El verbo existencial ser no lleva incorporado ningún clítico. Puede aparecer con el clítico locativo hi pero este no será impersonalizador y siempre podrá ser sustituido por un SP o un SAdv, tal como se muestra en (20).

(20) a. Tu hi seràs. tu loc. serás «Tú estarás»

b. Tu seràs a la universitat. «Tú estarás en la universidad»

Tal como se demuestra en (20) con la presencia del pronombre de segunda personal, las frases con el existencial ser son personales, frases en las que existe nominativo. En cambio, en las construcciones con ser existencial el SN tema no aparecerá nunca en acusativo. El verbo ser no asigna acusativo ni cuando es un verbo existencial o locativo ni cuando es un verbo copulativo. De ahí que el tema de la frase deba aparecer en nominativo. Es el único caso que queda a su disposición, ya que el verbo no es transitivo.

A pesar del parecido entre el verbo ser existencial y el verbo ser copulativo en relación a la incapacidad de ambos verbos de asignar caso, en algunos dialectos se comportan diferentemente a la hora de aparecer en participio pasado. En la mayoría de dialectos del catalán, el verbo ser, sea copulativo sea 
existencial, carece de una forma de participio pasado propia. Para expresar el participio pasado del verbo ser se usa, en realidad, el del verbo estar (se), verbo que significa no moverse, permanecer un tiempo en alguna parte. Así lo muestran las frases de (21).

(21) a. El director ha estat comunista. (verbo copulativo) «El director ha sido comunista»

b. El director no ha estat aquí (verbo existencial) «El director no ha estado aquí»

Si embargo, el dialecto central —entre otros- sí posee una forma para el participio pasado del verbo ser cuando éste actúa como verbo copulativo: es el participio sigut que aparece en (22)

(22) a. El director havia sigut comunista. (catalán central) «El director había sido comunista»

b. Jo també he sigut jove. «Yo también he sido joven»

Ahora bien, cuando el verbo ser es existencial no es posible usar el participio pasado sigut ni siquiera en aquellos dialectos en los que las frases de (22) son perfectamente gramaticales. Hay que usar el participio pasado de otro verbo: estar-(se), ir, venir, etc. Así, (23a) y (23b) están bien formadas, pero $(23 \mathrm{c}) \mathrm{no}^{6}$.

(23) a. El director no és a la reunió. el director no es en la reunión «El director no está en la reunión»

b. El director no era a la reunió el director no era en la reunión «El director no estaba en la reunión»

c. ${ }^{*}$ El director no ha sigut a la reunió. el director no ha sido en la reunión

d. El director no ha estat/anat/vingut a la reunió. «El director no ha estado/ido/venido en/a la reunión»

6 Para una explicación teórica de la ausencia de una forma de participio pasado propia del verbo ser véase Rigau (1993). 
3. Hecha la presentación general del comportamiento sintáctico de los verbos existenciales o locativos haver- $h i$ y ser, pasamos a analizar el comportamiento de dichos predicados en los diferentes dialectos del catalán.

\subsection{CATALÁN NOROCCIDENTAL}

Si el verbo es haver-hi, el catalán noroccidental no establece concordancia entre el tema y el verbo. Así, en este dialecto (24a) y (24b) están mal formadas.

(24) a. Hi ha els estudiants. loc. ha los estudiantes «Están los estudiantes»

b. Hi ha estudiants. loc. ha estudiantes «Hay estudiantes»

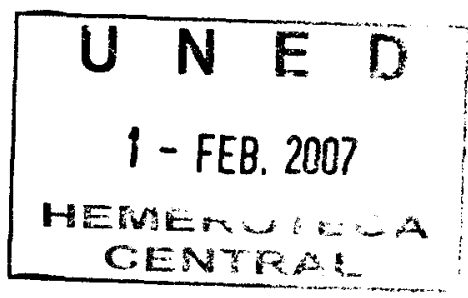

c. ${ }^{*} H i$ han els estudiants. loc. han los estudiantes.

d. *Hi han estudiants. loc. han estudiantes

Las frases (24a) y (24b) son impersonales, el tema del predicado se comporta como un verdadero objeto directo. Lo mismo ocurre en construcciones como las de (25a) y (25c) donde el elemento impersonalizador es ahora el clítico seles arbitrario.

(25) a. Enguany es plantarà arbres. este año se plantará árboles «Este año se plantarán árboles»

b. *Enguany es plantaran arbres. este año se plantarán árboles

c. Demà es plantarà els arbres. mañana se plantará los árboles «Mañana se plantarán los árboles» 
d. *Demà es plantaran els arbres. mañana se plantarán los árboles

También se presentan como estructuras impersonales las frases constituidas por un verbo inacusativo - venir, arribar «llegar», entrar, etc. - y un tema formado por un SN no definido. Véase en (26).

(26) a. Ve pluges.

viene lluvias

«Vienen lluvias»

b. *Vénen pluges.

vienen lluvias

c. M'arribava moltes cartes.

me llegaba muchas cartas

«Me llegaban muchas cartas»

d. *M'arribaven moltes cartes.

me llegaban muchas cartas

Las frases de (24)-(26) muestran que en noroccidental no se da concordancia entre el tema y el verbo en las construcciones impersonales. Nada tiene de extraño, pues, que una frase impersonalizada por la presencia del clítico $h i$, se comporte como las frases en las que el agente queda absorbido por el clítico $s e^{7}$.

Cuando el verbo existencial es el verbo ser, la frase no puede ser impersonal. Las frases existenciales con el predicado ser del noroccidental no se diferencian, pues, de las del catalán central. Así, las frases de (20) son frases que además de pertenecer a otros dialectos pertenecen también al noroccidental.

7 Sobre las construcciones de (24)-(26) del noroccidental, véase Solà (1973) y Rigau (1991). La gramática normativa acepta la ausencia de concordancia en (24), pero condena esta ausencia en las construcciones de (25) y (26). 


\subsection{CATALÁN CENTRAL}

Si el verbo de la frase es haver-hi, el catalán central tiende a concordar el tema con el verbo. En consecuencia, las frases de (24) que resultaban agramaticales en noroccidental son gramaticales en catalán central, mientras que las frases gramaticales del noroccidental no son propias del central, aunque sean las construcciones aceptadas por la gramática normativa.

(27) a. Hi han els estudiants.

loc. han los estudiantes

«Están los estudiantes»

b. Hi han estudiants.

loc. han estudiantes

«Hay estudiantes»

Proponemos que las frases de (27) del catalán central son tan impersonales como sus equivalentes (24a) y (24b) del noroccidental. Lo que las diferencia es el hecho de que el tema u objeto verbal concuerde en número con el verbo. Obsérvese que no consideramos que exista concordancia de persona en (27). La frase es impersonal debido a la presencia del clítico $h i$.

En Rigau (1991) se muestra que la propiedad oracional de persona permite al sujeto recibir nominativo, mientras que la concordancia en número es la manifestación de la relación que se establece entre el verbo y el argumento del que el verbo predica. La concordancia en número marca la relación especial existente entre el predicado y su argumento prominente. Si la frase posee un sujeto en nominativo, un argumento externo al SV, entonces éste será el argumento prominente de la predicación y, por lo tanto, existirá concordancia en número entre el sujeto y el verbo.

La diferencia dialectal aparece cuando la frase no es personal, cuando no existe un argumento externo en nominativo. En este caso, hemos visto en el apartado 3.1 que el catalán noroccidental no marca como prominente a ningún argumento. Es decir, en noroccidental sólo son considerados argumentos prominentes de la predicación los que reciben nominativo, los de las frases no impersonales. En catalán central, en cambio, la concordancia en número entre el verbo y uno de sus argumentos es obligatoria. Si el verbo posee un argumento externo nominativo, éste será el argumento considerado prominente de la predicación. Si, por lo contrario, la frase es impersonal entonces el argumento interno —en caso de existir- se interpretará como el argumento prominente de la predicación y expresará concordancia morfológica en número con el verbo. 
En otras palabras, lo que realmente diferencia el catalán central del noroccidental es que, en el dialecto central, el SN tema de (27) es interpretado como el argumento prominente de la predicación, de ahí que concuerde en número con el verbo. Esta concordancia se establece a pesar de que el SN tema no reciba nominativo, como bien prueba el hecho de que no pueda ser sustituido el SN tema por el pronombre ells «ellos» ((16a)*Hi han ells). En el dialecto noroccidental, la ausencia de la propiedad de persona en la frase provoca la ausencia de la propiedad de número, de ahí que no exista concordancia entre el SN tema y el verbo en las frases impersonales.

La misma situación se observa en las construcciones con el clítico seles arbitrario. De nuevo el dialecto central y el noroccidental invierten los valores de gramaticalidad. Las construcciones $(28 \mathrm{a})$ y $(28 \mathrm{c})$, que eran gramaticales en noroccidental, son agramaticales en catalán central, mientras que las frases (28b) y (28d), mal formadas en noroccidental, son perfectas en el dialecto central, ya que el objeto verbal está considerado como el argumento prominente de la frase que debe concordar en número con el verbo. A causa de la presencia del clítico seles, no hay lugar en estas construcciones para un argumento externo agente.

(28) a. *Enguany es plantarà arbres. este año se plantará árboles

b. Enguany es plantaran arbres. «Este año se plantarán árboles»

c. *Demà es plantarà els arbres. mañana se plantará los árboles

d. Demà es plantaran els arbres. «Mañana se plantarán los árboles»

En las frases impersonales con verbos inacusativos, el dialecto central invierte una vez más los valores de gramaticalidad del noroccidental, puesto que la ausencia de la propiedad de persona en la frase no impide la concordancia en número en el catalán central. Así lo muestran los datos de (29).

(29) a. *Ve pluges. viene lluvias

b. Vénen pluges. «Vienen lluvias» 

c. *M'arribava moltes cartes. me llegaba muchas cartas
d. M'arribaven moltes cartes. «Me llegaban muchas cartas»

Las construcciones de (28) y (29) nos permiten demostrar que la concordancia observada en (27) entre el verbo y su tema nada tiene de especial. Esta responde a una característica general del catalán central según la cual la ausencia de la propiedad oracional de persona no impide la presencia de la propiedad oracional de número expresada a través de la concordancia entre el verbo y el SN objeto, convertido en estas construcciones sin sujeto en el argumento màs prominente de la predicación.

En el catalán central, las frases existenciales con el verbo ser no difieren de lo comentado en el apartado 2.2.

\subsection{ALGUERÉS}

El comportamiento de los predicados existenciales o locativos en el catalán alguerés no coincide exactamente ni con el catalán noroccidental ni con el central. Compárense las siguientes frases del alguerés con las del noroccidental.

(30) a. Hi ha un home (alguerés) «Hay un hombre»

b. Hi havia llibres. «Había libros»

c. *Hi haurà/hauran los hòmens. loc. habrá/habrán los hombres.

(31) a. Hi ha un home (catalán noroccidental). «Hay un hombre»

b. Hi havia llibres. «Había libros»

c. Hi haurà els homes. loc. habrá los hombres 
Las frases de (30) muestran que en alguerés haver-hi aparece sólo con SSNN no definidos y que no se da concordancia entre el tema y el verbo. Las frases de (31) muestran, en cambio, que el tema de haver-hi en catalán noroccidental puede ser un SN definido. De ello deducimos que el verbo haver-hi en alguerés asigna a su objeto solamente caso partitivo, mientras que este mismo verbo en catalán noroccidental o central puede asignar caso partitivo o caso acusativo.

Compárense seguidamente las frases algueresas de (32) y las de (33), pertenecientes al catalán central y al noroccidental.

(32) a. *Hi seran hòmens. (alguerés)

loc. serán hombres

b. Hi era el cavall. loc. era el caballo

c. El cavall hi era. el caballo loc. era «El caballo estaba (aquí/allí)»

(33) a. *Hi seran homes. (catalán central/noroccidental) loc. serán hombres

b. *Hi era el cavall. loc. era el caballo

c. El cavall hi era. el caballo loc. era «El caballo estaba (aquí/allí)»

La construcción agramatical de (33a) muestra que en alguerés como en los demás dialectos catalanes, ser, no puede aparecer con un tema formado por un SN sin determinante (un SN no específico), ya que este verbo no asigna caso partitivo. Más interesantes son los ejemplos (32b) y (33b). Lo que es agramatical en catalán central o noroccidental es gramatical en alguerés.

¿Por qué en alguerés es posible el tema posverbal en las frases con el verbo $s e r$ cuando ello no es posible ni en catalán central ni en noroccidental? $\mathrm{La}$ respuesta hay que buscarla en las condiciones de economía que rigen las lenguas $^{8}$. Empecemos por analizar la frase $(32 b)$. Esta frase, en la que el sujeto

8 Para una nueva reinterpretación de las condiciones de economía linguística, consúltese Chomsky (1992). 
está en posición posverbal, es parecida a las de (34), en las que el sujeto es también posverbal y recibe interpretación de foco oracional. ${ }^{9}$.

(34) a. Ha canviat els llibres de lloc la teva germana.

b. Ha cambiado los libros de sitio tu hermana.

Obsérvese que a las frases de (34) se les podría añadir y no tu prima, ya que en (34) no sólo se afirma que el agente de la acción de cambiar los libros de sitio ha sido tu hermana, sino que a la vez se niega que haya llevado a cabo la acción quien el interlocutor presupone. Vemos, pues, que en catalán, como en español, el elemento en posición final de frase puede recibir interpretación de foco oracional.

¿Por qué en las frases con el verbo existencial ser el alguerés permite que el SN nominativo aparezca en posición final de frase y no lo permiten el catalán central y el noroccidental? La razón podría ser la siguiente: el catalán central y el noroccidental ya tienen la posibilidad de tener el tema de un verbo existencial en posición final de frase $\longrightarrow$ posición desde la que puede recibir interpretación de foco oracional- a través de las estructuras con el predicado haver-hi, tal como se ve en (35).

(35) Hi havia el cavall (catalán central/noroccidental)

loc. había el caballo

«Estaba el caballo»

En alguerés, sin embargo, (35) no es posible, porque el predicado haverhi no asigna en este dialecto caso acusativo a su tema. Así pues, al alguerés le estará permitido un tema posverbal con el verbo ser, ya que esta es la única vía que posee para focalizar el tema de las frases existenciales. De ahí que la frase (32b): Hi era el cavall sea posible en este dialecto. En resumen: lo que impide al catalán central y al noroccidental tener frases como (32b) es la existencia de la construcción (35). Como en alguerés (35) no existe, (32b) queda legitimada, ya que este dialecto no posee otra vía para focalizar el tema en las frases existenciales ${ }^{10}$.

\footnotetext{
${ }^{9}$ Sobre los sujetos posverbales del catalán y la interpretación de foco, véase Bonet (1989).

10 Véase J. Pais (1970) sobre la preferencia de uso del verbo ser existencial cuando el modo de la construcción no es el indicativo.
} 


\subsection{BALEÁRICO}

Los verbos existenciales del catalán baleárico presentan un comportamiento más próximo al del catalán noroccidental que al del catalán central. El verbo haver-hi puede tener por tema tanto un $\mathrm{SN}$ indefinido como un SN definido - como en catalán central y en noroccidental-, pero el tema no concuerda en número con el verbo.

(36) a. Hi havia dones.

loc. había mujeres

«Había mujeres»

b. Hi havia ses dones. loc. había las mujeres

«Estaban las mujeres»

c. *Hi havien ses dones.

loc. habían las mujeres

Sin embargo, esta coincidencia que acabamos de observar entre el baleárico y el noroccidental se pierde en las estructuras con el clítico es/se arbitrario o con un verbo inacusativo. Así, las construcciones de (37), que hemos visto que estaban bien formadas en noroccidental, son agramaticales en baleárico. Las de (38), en cambio, resultan gramaticles en baleárico y agramaticales en noroccidental.

(37) a. *Demà es plantarà arbres. mañana se plantará árboles

b. *Ve pluges. viene lluvias

(38) a. Demà es plantaran arbres. «Mañana se plantarán árboles»

b. Vénen pluges. «Vienen lluvias»

A través de estos datos, vemos que, por lo que se refiere a la concordancia en número entre un argumento y el verbo en las frases impersonales, el baleárico sólo se aparta de catalán central cuando el verbo es haver-hi. 


\subsection{VALENCIANO}

El rasgo más llamativo de las construcciones existenciales del valenciano es la pérdida del predicado ser a favor del predicado existencial o locativo estar. Así pues, la construcción de (39), ausente en otros dialectos catalanes, es gramatical en los diferentes dialectos valencianos.

(39)

Els xiquets no estan ací.

«Los niños están aquí»

Otra característica del valenciano es la pérdida del pronombre adverbial $h i$, que ya sólo se conserva cuando está léxicamente incorporado a un verbo, como es el caso de haver-hil ${ }^{11}$ y de los verbos de percepción sentir-hi «tener capacidad auditiva», vore-s' $h i$ «tener capacidad de visión», etc.

En valenciano, el comportamiento del verbo haver-hi no coincide plenamente con ninguno de los dialectos anteriormente reseñados. por una parte, el valenciano coincide con el catalán central. Por otra, coincide con el alguerés. Así, el valenciano - como el catalán central- presenta concordancia entre el tema de haver-hi y el verbo.

(49) Hi havien xiquets.

loc. habían niños

No obstante este paralelismo con el catalán central, el valenciano no utiliza el predicado haver-hi si el tema es un SN definido. En esto, pues, el valenciano coincide con el alguerés. Sin embargo, a diferencia del alguerés, el verbo utilizado en valenciano cuando el tema es definido no será ser. Será el verbo estar.

(41) a. *Hi halhan els xiquets.

loc. ha/han los niños

b. Estan els xiquets.

«Están los niños»

11 En algunos dialectos valencianos se incorpora a este predicado el clítico partitivo en haver-n' $h i$, E. g., N'hi ha cafè «Hay café». 


\subsection{ROSELLONÉS}

Este dialecto catalán ha recibido y recibe aún una fuerte influencia del francés. Es por ello por lo que tiende a usar los verbos existenciales haver-hi y ser como los usa el francés. Por lo tanto, no se establecerá concordancia entre el verbo haver-hi y su tema.

(42) Hi haurà dos homes. loc. habrá dos hombres «Habrá dos hombres»

Asimismo, si el tema de la frase existencial es un SN definido la frase suele construirse con el verbo ser. Como en francés, el predicado haver-hi se reserva para las construcciones con un SN no definido como tema.

4. Aquí acaba esta exposición sobre las construcciones existenciales o locativas del catalán. Es conveniente recordar que la atención a los dialectos de una lengua no ha de ser objetivo exclusivo de los dialectólogos, sino también de los que nos dedicamos al estudio sintáctico, ya sea desde el punto de vista descriptivo o desde un punto de vista más teórico. La comparación interdialectal facilita la comprensión de las propiedades sintácticas de la lengua. Lo que no se hace evidente en un dialecto puede que sea patente en otro.

\section{BIBLIOGRAFÍA}

BONET, E. (1989) «Postverbal Subjects in Catalan» ms. MIT.

BONET, E. (1991) Morphology after Syntax: Pronominal Clitics in Romance, tesis doctoral, MIT.

Chomsky, N. (1992) «A Minimalist Program for Linguistic Theory», MIT Occasional Papers in Linguistics, 1, MIT, Cambridge.

Colomina I CASTAÑER, J. (1985) L'alacantí. Un estudi sobre la variació lingüistica, Institut d'Estudis «Juan Gil-Albert», Alacant.

FABRA, P. (1956) Gramàtica catalana, Teide, Barcelona.

Gràcla, L. (1989) La teoría temàtica, Publicacions dels departaments de Filologia catalana i de Filologia Espanyola, UAB, Bellaterra.

MoLL, F. (1968) Gramàtica catalana referida especialment a les Illes Balears, Raixa, Palma de Mallorca. 
PAIS, J. (1970) Gramàtica algueresa, vol. 1, Barcino, Barcelona.

RigaU, G. (1991) «On the Functional Properties of AGR», Catalan Working Papers in Linguistics, 1991, UAB, Bellaterra, pp. 235-260.

RIGAU, G. (1993) «Alternancia ser/haver-hi en las frases existenciales del catalán», comunicación presentada en el Tercer Coloquio de Gramática Generativa, San Lorenzo de El Escorial, marzo-abril 1993.

Torrego, E. (1989) «Unergative-Unaccusative Alternations in Spanish», MIT Working Papers in Linguistics, vol. 10, MIT, Cambridge, pp. 253-272.

SAlvadOR, C. (1974) Gramàtica valenciana, Publicacions de Lo Rat Penat, València

SolÀ, J. (1973), Estudis de sintaxi catalana/2, Edicions 62, Barcelona.

SOLÀ, J. (1987) Questions controvertides de sintaxi catalana, Edicions 62, Barcelona.

VENY, J. (1978) Els parlars, Dopesa, Barcelona. 